\title{
Glycemic Control Rate in Patients With Type 1 Diabetes Treated at a Public Tertiary Referral Hospital in Rio de Janeiro, Brazil
}

\author{
Raissa Barros Mota ${ }^{\mathrm{a}}$, Elisa Baranski Lamback ${ }^{\mathrm{a}}$, Natasha Reis Lozovey ${ }^{\mathrm{a}}$, Michelle Botelho Caarls ${ }^{\mathrm{b}, \mathrm{c}}$, \\ Mariana Arruda ${ }^{\mathrm{d}}$, Leonardo Vieira Neto ${ }^{\mathrm{a}, \mathrm{d}}$, e
}

\begin{abstract}
Background: The incidence of type 1 diabetes (T1D) has been increasing worldwide, leading to a serious public health problem resulting in reduced life expectancy and increased morbidity. The aim of this study was to determine the glycemic control rate and its demographic and clinical factors, in T1D followed up at a tertiary referral hospital in Brazil.
\end{abstract}

Methods: An observational and retrospective study was conducted between October 2014 and October 2015. Data were obtained from 140 medical records.

Results: Satisfactory glycemic control rate was found in $22.14 \%$ of patients. There was no difference between the pediatric group and adult group regarding control rate. However, a worse HbA1C level was found in the pediatric group $(\mathrm{P}=0.001)$. The use of long-acting insulin analogue $(\mathrm{P}=0.03)$ was associated with satisfactory glycemic control, and a tendency was observed for both the combination of long-acting and ultra-rapid acting analogues $(\mathrm{P}=0.08)$, and the absence of ketoacidosis during the course of diabetes $(\mathrm{P}=0.08)$. In the group with satisfactory glycemic control, the median number of consultations $(1(1-4))$ was significantly lower than in the uncontrolled group $(2(1-4))(P=0.003)$. Regarding the two major microvascular complications, $23.53 \%$ had retinopathy and $12.09 \%$ had nephropathy.

Conclusions: The majority of patients did not obtain a satisfactory

Manuscript accepted for publication August 22, 2016

aEndocrinology Section, Hospital Federal da Lagoa, Rua Jardim Botanico, 501 - Jardim Botanico, 22470-050 Rio de Janeiro, RJ, Brazil

bInstitute of Biomedical Sciences, Universidade Federal do Rio de Janeiro, Rua Professor Rodolpho Paulo Rocco, 255 - Ilha do Fundao, 21941-913 Rio de Janeiro, RJ, Brazil

${ }^{c}$ Laboratorio de Inflamacao, Institute of Biophysics Carlos Chagas Filho, Universidade Federal do Rio de Janeiro, Rua Professor Rodolpho Paulo Rocco, 255 - Ilha do Fundao, 21941-913 Rio de Janeiro, RJ, Brazil

${ }^{\mathrm{d}}$ Department of Internal Medicine and Endocrinology Section, Medical School and Hospital Universitario Clementino Fraga Filho, Universidade Federal do Rio de Janeiro, Rua Professor Rodolpho Paulo Rocco, 255 - Ilha do Fundao, 21941-913 Rio de Janeiro, RJ, Brazil

eCorresponding Author: Leonardo Vieira Neto, Rua Professor Rodolpho Paulo Rocco, 255. Ninth floor. Endocrine section. Ilha do Fundao, Rio de Janeiro, RJ, Brazil. Email: netolv@gmail.com

doi: http://dx.doi.org/10.14740/jem369w
HbA1C level. Good glycemic control factors were directly associated with the use of long-acting insulin analogues, and the combination of long-acting and ultra-rapid analogues as well as the absence of ketoacidosis during T1D's evolution tended also to be associated with better metabolic control.

Keywords: Type 1 diabetes mellitus; Glycosylated hemoglobin A; Brazil

\section{Introduction}

Type 1 diabetes (T1D) is a heterogeneous disorder characterized by the destruction of pancreatic beta cells, gradually leading to absolute insulin deficiency $[1,2]$.

The International Diabetes Federation (IDF) estimates that 415 million individuals between 20 and 79 years old have diabetes, with a worldwide prevalence of $8.8 \%$ [3]. Among children and adolescents with T1D aged up to 14 years, an overall incidence and prevalence of 86,000 per year and 542,000 are estimated, respectively [3]. In Brazil, the estimated incidence and prevalence correspond to 5.0/1,000/year and 31.1/1,000, respectively [4]. The epidemiology of T1D in adults is less well characterized than in children aged 0 - 14 years old. Studies show that T1D incidence has been increasing approximately $3 \%$ each year $[5-8]$.

T1D is a chronic disease, usually diagnosed in children and young adults, requiring indefinite multidisciplinary treatment, making it an extremely onerous disease. In Brazil, for example, an average annual cost of US $\$ 1,319.15$ per patient is estimated for nominal T1D treatment [9]. Moreover, T1D has an important negative impact on life quality and expectancy, mainly due to the disease-specific vascular complications [10].

After the Diabetes Control and Complications Trial (DDCT) and later, the Epidemiology of Diabetes Interventions and Complications (EDIC) results were published, it became clear that diabetic complications were directly related to poor glycemic control, recognizing the need of achieving the best glycemic and metabolic control as soon as T1D diagnosis is established [11-13]. Despite this knowledge, it is extremely difficult to achieve strict glycemic control in clinical practice.

This study aims to assess glycemic control rate and its demographic and clinical factors, and analyze the prevalence of microvascular complications in patients with T1D in a public 
Brazilian tertiary referral hospital.

\section{Materials and Methods}

\section{Study design and population}

An observational, retrospective study, between October 2014 and October 2015, at the Endocrinology Section of Hospital Federal da Lagoa (HFL) was performed. All patients were seen by an endocrinologist. Inclusion criteria were predefined as follows: patients (adults and children) diagnosed with T1D, with a regular follow-up and at least one visit and a glycated hemoglobin $(\mathrm{HbA} 1 \mathrm{C})$ assessment during the studied period. Exclusion criteria included: 1) other types of diabetes (such as type 2 diabetes, latent autoimmune diabetes in adults (LADA), maturity-onset of diabetes of the young, and gestational diabetes); 2) an irregular follow-up with no medical appointment in the studied period; 3 ) patients treated with another option besides insulin injections (including insulin pump); and 4) those with unavailable $\mathrm{HbA1C}$ measurement.

\section{Data collection}

The following data were collected from data available in medical records: age at the last consultation, age at diagnosis (in years), gender, diabetes duration (in months), type of insulin, self-monitoring of blood glucose (SMBG), presence and frequency of hypoglycemia with the latest treatment, history of diabetic ketoacidosis, presence of nephropathy or retinopathy, body mass index (BMI), waist circumference and HbAlC.

According to age range, the participants were divided into two groups: individuals aged 18 years or less were included in the pediatric group and above 18 years in the adult group. Three groups were created to classify the type of insulin injection: intermediate insulin $(\mathrm{NPH})+$ rapid insulin (regular), intermediate insulin + ultra-rapid insulin analogue (glulisine, lispro or aspart), or long-acting insulin analogue (detemir, glargine or degludec) + ultra-rapid insulin analogue. SMBG was analyzed through glycemic profile and divided into: $<1$ time/day; 1 - 3 times/day and $>4$ times/day. BMI was determined dividing the weight in $\mathrm{kg}$ by the square of the height in meter, and considered normal below the 85 th percentile adjusted for age and sex for participants younger than 20 years of age and below $25 \mathrm{~kg} / \mathrm{m}^{2}$ for adults $\geq 20$ years old. Overweight and obesity were classified as a BMI between p85 and p94 adjusted for age and sex for individuals $<20$ years of age or BMI between 25 and 30 for adults $\geq 20$ years of age, and $\geq$ 95 th percentile for participants $<20$ years of age and BMI $\geq$ $30 \mathrm{~kg} / \mathrm{m}^{2}$ for adults $\geq 20$ years of age, respectively [14]. Waist circumference was measured at midpoint between the lowest rib and the iliac crest [14].

$\mathrm{HbA1C}$ was determined by high performance liquid chromatography, a certified method by the Glycohemoglobin Standartization Program, in the equipment Premier Hb9210 ${ }^{\mathrm{TM}}$, with the software Affinity ${ }^{\mathrm{TM}}$, with an acceptable error range of 0.067. Satisfactory control target was defined as an HbA1C lower than $7.5 \%$ for children and adolescents aged up to 18 years old and below $7.0 \%$ for patients older than 18 years old, according to the American Diabetes Association (ADA) and the International Society for Pediatric and Adolescent Diabetes (ISPAD) [2, 15].

Patients who had more than 5 years of diabetes were analyzed regarding the two major microvascular complications: 1) nephropathy was assessed by identifying the presence of urine albumin-to-creatinine ratio $>30 \mathrm{mg} / \mathrm{g}$ in a random spot urine collection or albuminuria $>30 \mathrm{mg} / 24 \mathrm{~h}$ urine [16]; and 2) retinopathy was screened with fundoscopic examination performed at the Ophthalmology Section, and considered positive when microvascular alterations leading to retinal ischemia or neovascularization were present [17]. In other words, if mild, moderate or severe non-proliferative retinopathy or proliferative retinopathy was present.

Diabetic neuropathy was not analyzed due to the lack of standardization of different test methods.

\section{Statistical analysis}

The statistical analyses were performed using SPSS version 20.0 for MacOS (SPSS Inc., Chicago, IL). Most of the variables, except BMI and waist circumference, were found not to follow a normal distribution using the Kolmogorov-Smirnov test. For the descriptive analysis, categorical variables were expressed as the percentage and frequency, and numerical variables were expressed as mean $\pm \mathrm{SD}$ or median (minimum - maximum) according to their distribution pattern. Student's $t$ test or the Mann-Whitney U test was performed to compare the numerical variables between the two groups according to their distributions. A Kruskal-Wallis test was performed to compare the numerical variables between the three groups (insulin injection and SMBG). Fisher's exact test and a Chi-square test were used to compare categorical variables. A P-value $<0.05$ was considered statistically significant, except for comparison between two of the three groups (insulin injection and SMBG), when P-value $<0.017$ was considered significant (Bonferroni post hoc analysis). P-values $\geq 0.05$ and $\leq 0.09$ were considered to indicate a tendency towards statistical significance.

\section{Results}

Out of 173 patients selected with T1D diagnosis, 33 were not eligible (18 patients were excluded due to unavailable $\mathrm{HbAlc}$, 11 did not have any consultation during the studied period and four had LADA). Clinical and epidemiological data of the 140 patients included in this study are shown in Table 1.

Regarding age at diagnosis, $78.58 \%$ of patients were diagnosed with T1D between 5 and 19.9 years. The majority of patients had one or two consultations per year $(70 \%)$ and most of them had $\geq 4$ blood glucose tests per day $(46.21 \%)$, while $43.94 \%$ performed $1-3$ tests daily and $9.85 \%$ less than once a day. Regarding the type of insulin, the majority (67.15\%) used intermediate-acting insulin instead of long-acting insulin analogue $(32.85 \%)$. Likewise, the majority $(55.71 \%)$ used ultra- 
Table 1. Clinical and Epidemiological Data

\begin{tabular}{|c|c|}
\hline Variables & Total, n (\%) \\
\hline Male/female & $70(50 \%) / 70(50 \%)$ \\
\hline $\operatorname{Age}^{\mathrm{a}}$ (years) & $19.0(6-64)$ \\
\hline $0-18$ & $69(49.30 \%)$ \\
\hline$>18$ & $71(50.70 \%)$ \\
\hline Age at diagnosis (years) & $10.0 / 1-33$ \\
\hline $0-5$ & $14(10 \%)$ \\
\hline $5-9.9$ & $50(35.72 \%)$ \\
\hline $10-14.9$ & $39(27.86 \%)$ \\
\hline $15-19.9$ & $21(15 \%)$ \\
\hline $20-29.9$ & $15(10.71 \%)$ \\
\hline$\geq 30$ & $1(0.71 \%)$ \\
\hline Diabetes duration (months) & $84(2-660)$ \\
\hline \multicolumn{2}{|l|}{ Treatment } \\
\hline Basal intermediate action insulin & $94(67.15 \%)$ \\
\hline Basal long duration analogues & $46(32.85 \%)$ \\
\hline Bolus rapid action insulin & $62(44.29 \%)$ \\
\hline Bolus ultra-rapid action insulin & $78(55.71 \%)$ \\
\hline \multicolumn{2}{|l|}{ Self-monitoring of blood glucose $(n=132)$} \\
\hline$<1$ time/day & $13(9.85 \%)$ \\
\hline $1-3$ times/day & $58(43.94 \%)$ \\
\hline$\geq 4$ times/day & $61(46.21 \%)$ \\
\hline Consultations/year & $2(1-4)$ \\
\hline 1 & $50(35.71 \%)$ \\
\hline 2 & $48(34.29 \%)$ \\
\hline 3 & $28(20 \%)$ \\
\hline 4 & $14(10 \%)$ \\
\hline Ketoacidosis at diagnosis $(\mathrm{n}=91)$ & $47(51.65 \%)$ \\
\hline Ketoacidosis during the evolution of the disease $(n=78)$ & $21(26.92 \%)$ \\
\hline Retinopathy $(\mathrm{n}=102)$ & $24(23.53 \%)$ \\
\hline Nephropathy $(\mathrm{n}=91)$ & $11(12.09 \%)$ \\
\hline Waist circumference $(\mathrm{cm})$ & $78.94 \pm 12.42$ \\
\hline $\operatorname{BMI}\left(\mathrm{kg} / \mathrm{m}^{2}\right)$ & $21.97 \pm 4.88$ \\
\hline Overweight or obesity $(n=104)$ & $39(27.85 \%)$ \\
\hline
\end{tabular}

aAge, patient's age obtained at the last consultation. BMI: body mass index.

rapid-acting insulin analogue instead of rapid-acting insulin (44.29\%). Moreover, $27.85 \%$ of patients were overweight or obese. Retinopathy was found in $23.53 \%$ and nephropathy in $12.09 \%$ of cases. All of the retinopathy cases and $90.90 \%$ of patients with nephropathy were diagnosed in adulthood (Table 1).

The global glycemic control rate was $22.14 \%$. Comparing the patients' profile according to age range, the median HbA1C level found in the pediatric group was significantly higher $(9.2 \%(5.2-16.5 \%))$ than in the adult group $(7.9 \%(5.6-$ $16.2 \%))(\mathrm{P}=0.001)$. However, there was no significant dif- ference regarding glycemic control rate between these groups $(21.74 \%$ and $22.53 \%$, respectively; $\mathrm{P}=0.910)$, nor regarding the median number of consultations per year $(2$ (1 - 4); $\mathrm{P}=$ 0.6).

Concerning the type of insulin, the group treated with long-acting analogue + ultra-rapid analogue tended to have a better control rate $(32.6 \% ; \mathrm{P}=0.08)$ and obtained a lower $\mathrm{HbA} 1 \mathrm{C}(7.90 \% ; \mathrm{P}=0.01)$ when compared to other groups $(\mathrm{Ta}-$ ble 2).

SMBG was more frequent in younger patients ( $\geq 4$ times/ day: 14 years old (6 - 56); 1 - 3 times/day: 21 years old ( 7 - 64); 
Table 2. Profile of Patients According to the Type of Insulin

\begin{tabular}{|c|c|c|c|c|}
\hline Variables & $\mathrm{NPH}+\mathrm{R}(\mathrm{n}=62)$ & NPH + UR $(n=32)$ & $L+U R(n=46)$ & Pvalue \\
\hline Sex & $\begin{array}{l}\mathrm{F}: 35(56.45 \%) \\
\mathrm{M}: 27(43.55 \%)\end{array}$ & $\begin{array}{l}\text { F: } 13(40.62 \%) \\
\text { M: } 19(59.38 \%)\end{array}$ & $\begin{array}{l}\text { F: } 22(47.83 \%) \\
\text { M: } 24(52.17 \%)\end{array}$ & NS \\
\hline Age $^{\mathrm{a}}$ (years) & $20(6-64)$ & $18.5(8-60)$ & $16.50(7-56)$ & NS \\
\hline Age at diagnosis (years) & $11.5(1-27)^{*}$ & $11.5(1-22)$ & $9.0(1-33)^{*}$ & 0.02 \\
\hline Diabetes duration (months) & $80(2-660)$ & $78(6-492)$ & $108(9-492)$ & NS \\
\hline BMI $\left(\mathrm{kg} / \mathrm{m}^{2}\right)$ & $22.38 \pm 4.92$ & $21.39 \pm 4.39$ & $21.87 \pm 5.22$ & NS \\
\hline Waist circumference $(\mathrm{cm})$ & $81.87 \pm 12.27$ & $71.13 \pm 8.87$ & $78.47 \pm 12.97$ & NS \\
\hline Hypoglycemia & $44 / 53(83 \%)$ & $18 / 24(75 \%)$ & $27 / 41(65.85 \%)$ & NS \\
\hline Retinopathy & $15 / 48(31.25 \%)$ & $1 / 22(4.54 \%)$ & $8 / 32(25 \%)$ & 0.05 \\
\hline Nephropathy & $6 / 44(13.63 \%)$ & $1 / 18(5.55 \%)$ & $4 / 29(13.79 \%)$ & NS \\
\hline $\mathrm{HbA1C}(\%)$ & $8.3(5.2-16.5)$ & $9.4(5.6-14.3)^{* *}$ & $7.9(6-11.3)^{* *}$ & 0.01 \\
\hline Control rate ${ }^{b}$ & $12 / 62(19.35 \%)$ & $4 / 32(12.50 \%)$ & $15 / 46(32.60 \%)$ & 0.08 \\
\hline
\end{tabular}

${ }^{a}$ Age, patient's age obtained at the last consultation. ${ }^{b}$ For this analysis, we considered ADA's goals for T1D patients as: $\mathrm{HbA} 1 \mathrm{C}<7.5 \%$ for children and adolescents up to 18 years old and $<7.0 \%$ for patients $\geq 18$ years old. *Significant difference between the groups: NPH $+R$ and $L+U R(P=0.006)$ - Kruskal-Wallis test and Bonferroni post hoc analysis. ${ }^{*}$ Significant difference between the groups NPH + UR and $L+U R(P=0.002)-$ Kruskal-Wallis test and Bonferroni post hoc analysis. BMI: body mass index; F: female; M: male; NS: not significant; NPH: (basal) intermediate insulin; R: (bolus) rapid insulin; L: (basal) long-acting insulin analogue; UR: (bolus) ultra-rapid insulin analogue.

$<1$ time/day: 20 years old $(10-38), \mathrm{P}=0.03)$, and in those using long-acting ( $\geq 4$ times/day: $69.05 \% ; 1$ - 3 times/day: $28.57 \%$; $<1$ time/day: $2.38 \%, \mathrm{P}=0.001)$ or ultra-rapid insulin analogues ( $\geq 4$ times/day: $56.94 \% ; 1$ - 3 times/day: $38.89 \%$; $<1$ time/day: $4.17 \%, \mathrm{P}=0.007)$. No statistical difference was found between SMBG and the presence of retinopathy or nephropathy.

The use of long-acting insulin analogue $(\mathrm{P}=0.03)$ was a factor of satisfactory glycemic control and a tendency was observed for combination of long-acting and ultra-rapid acting analogues $(\mathrm{P}=0.08)$, as well as for the absence of ketoacidosis during the course of diabetes $(\mathrm{P}=0.08)$. Regarding the group that had satisfactory glycemic control, the median number of consultations $(1(1-4))$ was significantly lower than in the uncontrolled group (2 (1 - 4)) $(\mathrm{P}=0.003)$ (Table 3).

SMBG was not a factor of glycemic control.

\section{Discussion}

In this study, we analyzed T1D patients' characteristics according to glycemic control rate, considering the cutoff points for age determined by ADA's and ISPAD's latest recommendations $[2,15]$. Only few studies in Brazil are available analyzing glycemic control, and trying to establish satisfactory glycemic control factors among T1D patients. In this series, satisfactory glycemic control rate was about $22 \%$, and the main positive factor of good control was the use of long-acting insulin analogue and the negative factor was the number of consultations per year. It is important to know which factors are associated with diabetes control not only for the patient's care but also to ensure effective health policies.

Studies conducted by the Brazilian Type 1 Diabetes Study
Group (BrazDiab1 SG) demonstrated a control rate of $23.2 \%$ and $11.6 \%$ among T1D younger than 18 years old and adults, respectively $[5,10]$. Previous Brazilian data showed an even worse control rate among T1D patients over 18 years old $(10 \%)$ [18]. Moreover, in a study that analyzed the control rate in Latin America, Chan et al [19] observed an overall control rate of $21.1 \%$. Regarding US data, where approximately $60 \%$ of the studied population were using insulin pump, considered to be the gold standard therapy for T1D, the control rate was $17-23 \%$ in patients younger than 18 years old, $14 \%$ in subjects aged 18 - 25 years old, and about $30 \%$ among adults over 25 years old, with a mean $\mathrm{HbA} 1 \mathrm{c}$ of $8.2-9.0 \%, 8.7 \%$ and $7.6-$ $7.7 \%$, respectively [20].

In our study, only $22.14 \%$ of the patients $(21.74 \%$ individuals $\leq 18$ years old and $22.53 \%$ adults $>18$ years old) reached the recommended goal, which is in agreement with that reported in the literature $[5,10,20,21]$. A greater number of consultations per year also did not imply in a better glycemic control. However, the difficulty of achieving satisfactory glycemic control in T1D is not exclusive to our service, as it appears to be global and should be seen as an important treatment challenge in T1D [5, 10, 19, 20, 22, 23]. Strict metabolic control plays an important role in preventing the onset and progression of chronic complications, as evidenced by the DCCT in which the progression of microvascular complications was so profoundly reduced in patients with intensive glucose control that the trial ended early after a mean time of 6.5 years, and all patients were placed into intensive therapy. This strict control should be sought even among children and adolescents from the beginning, as the early glycemic environment is remembered in target organs as a form of metabolic memory, mostly due to the existence of residual beta cell function. Hyperglycemia has long-lasting deleterious effects in diabetes and glycemic control, if not started at a very early stage of 
Table 3. Distribution of Patients According to Glycemic Control Rate

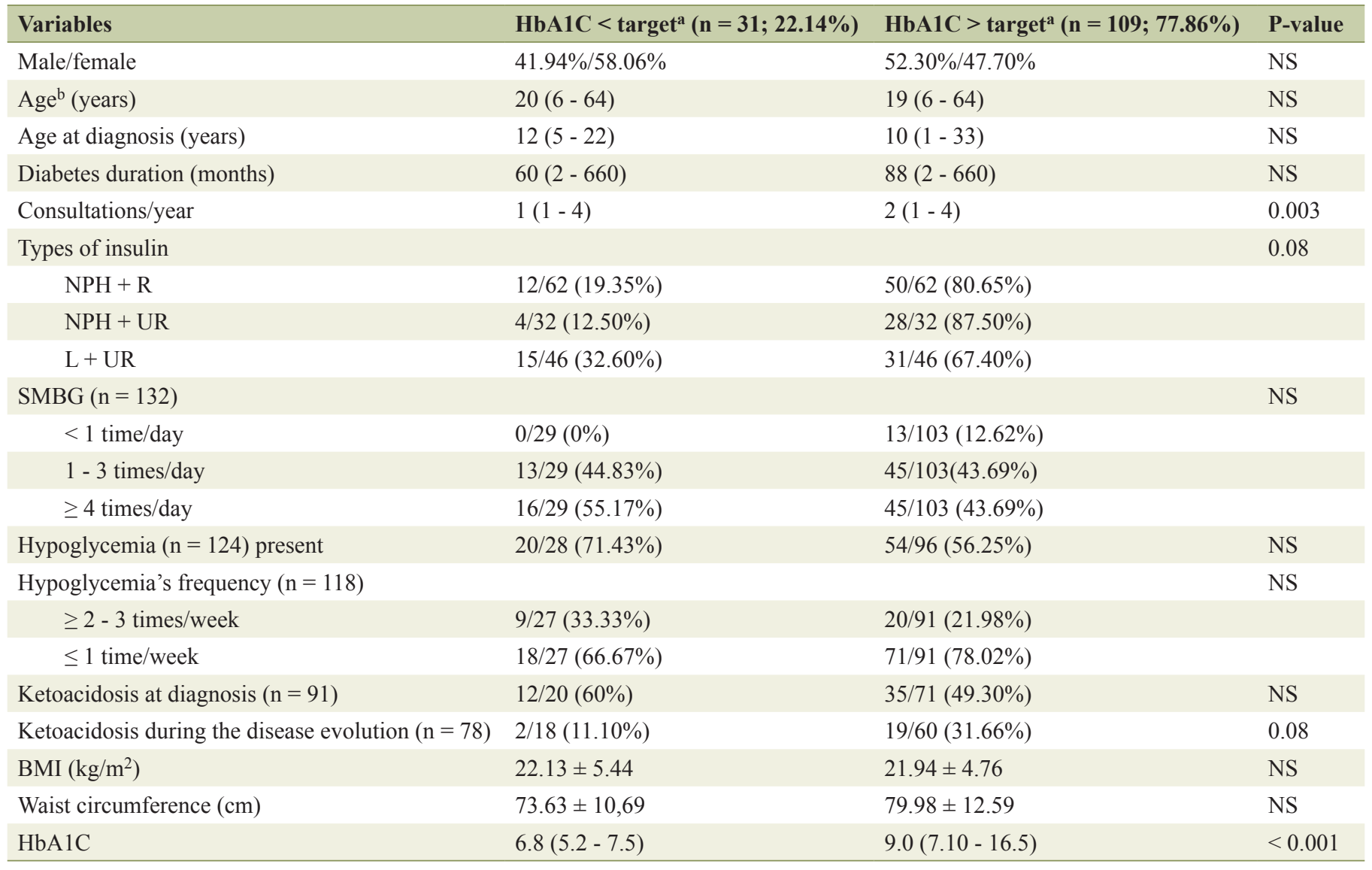

aFor this analysis, we considered ADA's goals for T1D patients as: $\mathrm{HbA} 1 \mathrm{C}<7.5 \%$ for children and adolescents up to 18 years old and $<7.0 \%$ for patients $\geq 18$ years old. ${ }^{b} \mathrm{Age}$, patient's age obtained at the last consultation. BMI: body mass index; HbA1C: glycated hemoglobin; L: long-acting insulin analogue; NPH: intermediate insulin; NS: not significant; R: rapid insulin; UR: ultra-rapid insulin analogue; SMBG: self-monitoring of blood glucose.

the disease. Strict metabolic control is associated with better glycemic control, lower hypoglycemia risk and long-lasting vascular benefits. Additionally, treatment optimization from the early stages of the disease significantly reduces the risks of complications [12].

There was no statistically significant difference between the pediatric group and adult group with respect to control rate; however, a worse $\mathrm{HbA} 1 \mathrm{C}$ level was found in the pediatric group, also consistent with literature data $[11,20]$. In the DCCT, for example, the intensively treated adolescent cohort achieved a mean $\mathrm{HbA} 1 \mathrm{c}$ of $8.06 \%$, whereas subjects in the corresponding adult cohort achieved a mean HbA1c of $7.1 \%$ [11]. In our study, this difference could be explained by the fact that our study gathered mostly adolescents $(65 \%$ of them during puberty), which, of all age groups, are currently the farthest from achieving target $\mathrm{HbA} 1 \mathrm{c}$ lower than $7.5 \%[21,22]$. Lack of concern regarding their disease, as well as psychological and hormonal changes can partially explain poor diabetes management during puberty. Moreover, both children and parents and even the medical team fear hypoglycemia, which may lead to overtreatment of initial symptoms, being more permissive in its treatment and instituting looser insulin regimens, even though the rates of hypoglycemia found in our study were similar in both the pediatric and adult groups [24-27].

In our study, although the use of ultra-rapid-acting insulin analogue was prescribed more often than regular insulin because it is routinely supplied in our hospital only for children and adolescents, its use did not correlate with better glycemic control when compared to rapid-acting insulin $(24.36 \%$ vs. $19.35 \%$ ), findings that are still controversial in the literature $[28,29]$. On the other hand, a better glycemic control rate was directly associated with the use of long-acting insulin analogues and a trend with the combination of long-acting and ultra-rapid analogues. Similarly, studies showed that the use of long-acting analogues was superior to intermediate-acting insulin leading to small but significant reduction in $\mathrm{HbAlc}$, as well as decrease in the frequency of severe and nocturnal hypoglycemia and mostly lower glycemic variability (nowadays considered as an additional marker of glucose control) $[30,31]$. In addition, a Brazilian study conducted in T1D patients showed superior control rate $(16.7 \%$ vs. $11.6 \%)$ with similar average $\mathrm{HbA} 1 \mathrm{c}$ in patients using long-acting insulin analogues, compared to findings from a multicenter study where different types of insulin regimens were used [5, 32]. Furthermore, considering $\mathrm{HbA} 1 \mathrm{C}$ as the outcome, no important clinical benefit was reported in systematic reviews per- 
formed in T1D patients comparing human insulins with insulin analogues [33]. Although ultra-rapid insulin analogues are superior to rapid-acting insulin regarding the reduction of postprandial hyperglycemia and severe hypoglycemia, its greater efficacy in reducing HbA1c is still debatable [28, 3335]. Despite the evident association between insulin analogues and a lower frequency of hypoglycemia, this finding was not observed in our study [28, 30, 31, 34, 35].

In our study, glycemic control tended to correlate to the type of insulin and presence of ketoacidosis during disease evolution. In addition, social and economic factors may also have contributed to glycemic control, since our hospital is a public institution whose attended population has lower economic and social status.

According to the literature, there is no consensus regarding which factors are directly associated with better glycemic control rates. Chan et al [19] noted that a short disease duration, SMBG and training by diabetes educators were associated with better glycemic control among patients with T1D in Latin America.

Furthermore, among our patients, $27.85 \%$ were overweight or obese. According to Gomes et al [10] in the BrazDiab1 study with T1D aged up to 18 years, $20.2 \%$ were overweight and $9.2 \%$ were obese. In another study by the same group, overweight was present in $25.6 \%$ and obesity in $6.9 \%$ of adults between 30 and 69 years [5]. Miller et al [20] observed a global rate of $25.65 \%$ and $16.4 \%$ in overweight and obesity, respectively.

Regarding SMBG, the optimal frequency in patients with T1D is unclear but ADA and ISPAD recommend that SMBG should be performed usually $4-6$ times a day $[15,21]$. In our study, most of the patients $(46.21 \%)$ had $\geq 4$ tests per day, while a minority $(9.85 \%)$ less than once a day, even though patients have access to inputs required to perform at least three tests daily. Several studies have demonstrated a strong correlation between SMBG frequency and glycemic control [15, 19, 21, 36-39], which was not observed in our study. A database study of almost 27,000 children and adolescents with T1D showed that increased daily frequency of SMBG was significantly associated with lower $\mathrm{HbA} 1 \mathrm{C}(-0.2 \%$ for one additional test per day) and with fewer acute complications [36].

Even though each patient was seen by an endocrinologist in a tertiary referral hospital, $27.15 \%$ did not undergo screening for retinopathy, which delays its early diagnosis and consequently the chance to treat and prevent further sequelae, also resulting in compromised quality of life of a significant proportion of our patients. This fact could be explained by the difficulties found when scheduling consultations and therefore having access to the Ophthalmology Service, which reinforces the importance of a specialized multidisciplinary team and the need to build partnerships. Likewise, despite the fact that microalbuminuria and/or albuminuria assessment is available in our hospital, $35 \%$ of our patients were not screened for diabetic nephropathy. Our findings were consistent with those found in other studies $[5,10,19]$.

Our study has some limitations. Since this is a retrospective study, the socio-economic analysis of the patients was impaired. Recently diagnosed $(<1$ year) T1D patients were not excluded to decrease the potential impact of residual insulin production, nor were analyzed factors that could interfere with $\mathrm{HbA1C}$, such as hemoglobinopathy.

In conclusion, achieving adequate control in T1D is difficult, which is seen globally. In our study, the majority did not have a satisfactory glycemic control rate. Good glycemic control factors were directly associated with the use of longacting insulin analogues, and the combination of long-acting and ultra-rapid analogues, as well as the absence of ketoacidosis during T1D's evolution tended also to be associated with better metabolic control.

\section{Acknowledgments}

We would like to thank the Endocrinology Section at HFL (Amanda Torres, Andreia Buzza, Andrea Ferreira, Carmine Osso, Daniel Bulzico, Deborah Zylberberg, Eline Romagna, Fabiana Melnik, Fernanda Junqueira, Helena Bandeira, Julia Souza, Lara Moreira, Roberto Zagury, Ronaldo Sinay, Samira Oliveira, Silvio Voscaboinik and Yasmine Ddine) and Hospital Federal da Lagoa's Diabetic's Association (ADILA).

\section{Conflicts of Interest}

The authors have nothing to declare.

\section{Author Contributions}

Study design: Leonardo Vieira Neto. Study conduct: Leonardo Vieira Neto and Raissa Barros Mota. Literature review: Leonardo Vieira Neto, Raissa Barros Mota, Elisa Baranski Lamback, Michelle Botelho Caarls and Mariana Arruda. Data collection: Raissa Barros Mota and Natasha Reis Lozovey. Data analysis: Leonardo Vieira Neto and Raissa Barros Mota. Data interpretation: Leonardo Vieira Neto, Raissa Barros Mota, Elisa Baranski Lamback, Michelle Botelho Caarls and Mariana Arruda. Drafting manuscript: Raissa Barros Mota and Elisa Baranski Lamback. Revising manuscript content: Leonardo Vieira Neto, Michelle Botelho Caarls and Mariana Arruda. Approving final version of manuscript: Leonardo Vieira Neto, Raissa Barros Mota, Elisa Baranski Lamback, Natasha Reis Lozovey, Michelle Botelho Caarls and Mariana Arruda. Leonardo Vieira Neto takes responsibility for the integrity of the data analysis.

\section{Abbreviations}

ADA: American Diabetes Association; BMI: body mass index; BrazDiab1 SG: Brazilian Type 1 Diabetes Study Group; DDCT: Diabetes Control and Complications Trial; EDIC: Epidemiology of Diabetes Interventions and Complications; F: female; HbA1C: glycated hemoglobin; HFL: Hospital Federal da Lagoa; IDF: International Diabetes Federation; ISPAD: International Society for Pediatric and Adolescent Diabetes; L: long-acting insulin analogue; M: male; NPH: intermediate in- 
sulin; NS: not significant; R: rapid insulin; SMBG: self-monitoring of blood glucose; T1D: type 1 diabetes; UR: ultra-rapid insulin analogue

\section{References}

1. (2) Classification and diagnosis of diabetes. Diabetes Care. 2015;38(Suppl):S8-S16.

2. Craig ME, Jefferies C, Dabelea D, Balde N, Seth A, Donaghue KC. ISPAD Clinical Practice Consensus Guidelines 2014. Definition, epidemiology, and classification of diabetes in children and adolescents. Pediatr Diabetes. 2014;15(Suppl 20):4-17.

3. Group IDFDA. Update of mortality attributable to diabetes for the IDF Diabetes Atlas: Estimates for the year 2013. Diabetes Res Clin Pract. 2015;109(3):461-465.

4. Patterson C, Guariguata L, Dahlquist G, Soltesz G, Ogle $\mathrm{G}$, Silink M. Diabetes in the young - a global view and worldwide estimates of numbers of children with type 1 diabetes. Diabetes Res Clin Pract. 2014;103(2):161-175.

5. Gomes MB, Coral M, Cobas RA, Dib SA, Canani LH, Nery M, de Freitas MC, et al. Prevalence of adults with type 1 diabetes who meet the goals of care in daily clinical practice: a nationwide multicenter study in Brazil. Diabetes Res Clin Pract. 2012;97(1):63-70.

6. Variation and trends in incidence of childhood diabetes in Europe. EURODIAB ACE Study Group. Lancet. 2000;355(9207):873-876.

7. Negrato CA, Dias JP, Teixeira MF, Dias A, Salgado MH, Lauris JR, Montenegro RM, Jr., et al. Temporal trends in incidence of Type 1 diabetes between 1986 and 2006 in Brazil. J Endocrinol Invest. 2010;33(6):373-377.

8. Incidence and trends of childhood Type 1 diabetes worldwide 1990-1999. Diabet Med. 2006;23(8):857-866.

9. Cobas RA, Ferraz MB, Matheus AS, Tannus LR, Negrato CA, Antonio de Araujo L, Dib SA, et al. The cost of type 1 diabetes: a nationwide multicentre study in Brazil. Bull World Health Organ. 2013;91(6):434-440.

10. Gomes MB, de Mattos Matheus AS, Calliari LE, Luescher JL, Manna TD, Savoldelli RD, Cobas RA, et al. Economic status and clinical care in young type 1 diabetes patients: a nationwide multicenter study in Brazil. Acta Diabetol. 2013;50(5):743-752.

11. Effect of intensive diabetes treatment on the development and progression of long-term complications in adolescents with insulin-dependent diabetes mellitus: Diabetes Control and Complications Trial. Diabetes Control and Complications Trial Research Group. J Pediatr. 1994;125(2):177-188.

12. The effect of intensive treatment of diabetes on the development and progression of long-term complications in insulin-dependent diabetes mellitus. The Diabetes Control and Complications Trial Research Group. N Engl J Med. 1993;329(14):977-986.

13. Nathan DM. The diabetes control and complications trial/ epidemiology of diabetes interventions and complications study at 30 years: overview. Diabetes Care. 2014;37(1):916.
14. Obesity: preventing and managing the global epidemic. Report of a WHO consultation. World Health Organ Tech Rep Ser. 2000;894:i-xii, 1-253.

15. (6) Glycemic targets. Diabetes Care. 2015;38(Suppl):S33-40.

16. (9) Microvascular complications and foot care. Diabetes Care. 2015;38(Suppl):S58-66.

17. Wu L, Fernandez-Loaiza P, Sauma J, Hernandez-Bogantes E, Masis M. Classification of diabetic retinopathy and diabetic macular edema. World J Diabetes. 2013;4(6):290294.

18. Mendes AB, Fittipaldi JA, Neves RC, Chacra AR, Moreira ED, Jr. Prevalence and correlates of inadequate glycaemic control: results from a nationwide survey in 6,671 adults with diabetes in Brazil. Acta Diabetol. 2010;47(2):137145.

19. Chan JC, Gagliardino JJ, Baik SH, Chantelot JM, Ferreira SR, Hancu N, Ilkova H, et al. Multifaceted determinants for achieving glycemic control: the International Diabetes Management Practice Study (IDMPS). Diabetes Care. 2009;32(2):227-233.

20. Miller KM, Foster NC, Beck RW, Bergenstal RM, DuBose SN, DiMeglio LA, Maahs DM, et al. Current state of type 1 diabetes treatment in the U.S.: updated data from the T1D Exchange clinic registry. Diabetes Care. 2015;38(6):971-978.

21. Rewers MJ, Pillay K, de Beaufort C, Craig ME, Hanas R, Acerini CL, Maahs DM. ISPAD Clinical Practice Consensus Guidelines 2014. Assessment and monitoring of glycemic control in children and adolescents with diabetes. Pediatr Diabetes. 2014;15(Suppl 20):102-114.

22. Wood JR, Miller KM, Maahs DM, Beck RW, DiMeglio LA, Libman IM, Quinn M, et al. Most youth with type 1 diabetes in the T1D Exchange Clinic Registry do not meet American Diabetes Association or International Society for Pediatric and Adolescent Diabetes clinical guidelines. Diabetes Care. 2013;36(7):2035-2037.

23. Eeg-Olofsson K, Cederholm J, Nilsson PM, Gudbjornsdottir S, Eliasson B. Glycemic and risk factor control in type 1 diabetes: results from 13,612 patients in a national diabetes register. Diabetes Care. 2007;30(3):496502.

24. (11) Children and adolescents. Diabetes Care. 2015;38(Suppl):S70-76.

25. Seaquist ER, Anderson J, Childs B, Cryer P, DagogoJack S, Fish L, Heller SR, et al. Hypoglycemia and diabetes: a report of a workgroup of the American Diabetes Association and the Endocrine Society. Diabetes Care. 2013;36(5):1384-1395.

26. Wysocki T, Harris MA, Mauras N, Fox L, Taylor A, Jackson SC, White NH. Absence of adverse effects of severe hypoglycemia on cognitive function in school-aged children with diabetes over 18 months. Diabetes Care. 2003;26(4):1100-1105.

27. Blasetti A, Chiuri RM, Tocco AM, Di Giulio C, Mattei PA, Ballone E, Chiarelli F, et al. The effect of recurrent severe hypoglycemia on cognitive performance in children with type 1 diabetes: a meta-analysis. J Child Neurol. 2011;26(11):1383-1391. 
28. Holcombe JH, Zalani S, Arora VK, Mast CJ. Comparison of insulin lispro with regular human insulin for the treatment of type 1 diabetes in adolescents. Clin Ther. 2002;24(4):629-638.

29. DeWitt DE, Hirsch IB. Outpatient insulin therapy in type 1 and type 2 diabetes mellitus: scientific review. JAMA. 2003;289(17):2254-2264.

30. Monami M, Marchionni N, Mannucci E. Long-acting insulin analogues vs. NPH human insulin in type 1 diabetes. A meta-analysis. Diabetes Obes Metab. 2009;11(4):372378.

31. Vardi M, Jacobson E, Nini A, Bitterman H. Intermediate acting versus long acting insulin for type 1 diabetes mellitus. Cochrane Database Syst Rev. 2008;3:CD006297.

32. Leite EB, Pedrosa HC, Casulari LA. Results of glycated hemoglobin during treatment with insulin analogues dispensed in the public health system of Federal District in Brazil. Diabetol Metab Syndr. 2015;7:66.

33. Schaan BD, Scheffel RS. Modern insulins, old paradigms and pragmatism: choosing wisely when deciding how to treat type 1 diabetes. Diabetol Metab Syndr. 2015;7:35.

34. Brunelle BL, Llewelyn J, Anderson JH, Jr., Gale EA, Koivisto VA. Meta-analysis of the effect of insulin lispro on severe hypoglycemia in patients with type 1 diabetes. Diabetes Care. 1998;21(10):1726-1731.

35. Haycox A. Insulin aspart : an evidence-based medicine review. Clin Drug Investig. 2004;24(12):695-717.

36. Ziegler R, Heidtmann B, Hilgard D, Hofer S, Rosenbauer J, Holl R. Frequency of SMBG correlates with HbA1c and acute complications in children and adolescents with type 1 diabetes. Pediatr Diabetes. 2011;12(1):11-17.

37. Schutt M, Kern W, Krause U, Busch P, Dapp A, Grziwotz $\mathrm{R}$, Mayer I, et al. Is the frequency of self-monitoring of blood glucose related to long-term metabolic control? Multicenter analysis including 24,500 patients from 191 centers in Germany and Austria. Exp Clin Endocrinol Diabetes. 2006;114(7):384-388.

38. Haller MJ, Stalvey MS, Silverstein JH. Predictors of control of diabetes: monitoring may be the key. J Pediatr. 2004;144(5):660-661.

39. Miller KM, Beck RW, Bergenstal RM, Goland RS, Haller MJ, McGill JB, Rodriguez H, et al. Evidence of a strong association between frequency of self-monitoring of blood glucose and hemoglobin A1c levels in T1D exchange clinic registry participants. Diabetes Care. 2013;36(7):2009-2014. 